\title{
Development of cardiovascular responses to hypoxia in larvae of the frog Xenopus laevis
}

\author{
REGINA FRITSCHE AND WARREN BURGGREN \\ Department of Biological Sciences, University of Nevada Las Vegas, Las Vegas, Nevada 89154-4004
}

\begin{abstract}
Fritsche, Regina, and Warren Burggren. Development of cardiovascular responses to hypoxia in larvae of the frog Xenopus laevis. Am. J. Physiol. 271 (Regulatory Integrative Comp. Physiol. 40): R912-R917, 1996.-Cardiovascular responses (blood pressure, heart rate, stroke volume, cardiac output, and peripheral vascular resistance) to acute hypoxia $\left(\mathrm{PO}_{2}=70 \mathrm{mmHg}\right)$ in developing larvae of Xenopus laevis from Nieuwkoop-Faber (NF) stage 45 and up to newly metamorphosed froglets were investigated. The results revealed two distinct response patterns to acute hypoxia in "early" (NF stages 45-48 and 49-51) and "late" (NF stages 52-53, 54-57, and 58-62) larval Xenopus. The early larvae responded to acute hypoxia with a significantly decreased stroke volume, cardiac output, and blood pressure. Peripheral resistance increased, whereas no change in heart rate occurred. In late larvae, stroke volume and blood pressure increased during acute hypoxia, but an offsetting bradycardia prevented major changes in cardiac output. We conclude that, up to stage 51 of development, hypoxia exerts a direct inhibitory effect on the heart and smooth muscle of the blood vessels, with no Frank-Starling relationship apparent. Older larvae show evidence of both intrinsic and extrinsic regulation of the cardiovascular system in response to acute hypoxia, suggesting that there is a specific point in larval development when cardiovascular regulation during hypoxia is expressed.
\end{abstract}

micropressure

THE DRAMATIC DEVELOPMENTAL changes occurring in amphibian cardiovascular and respiratory systems have received considerable attention in recent years (see review in Refs. 7, 10). In larval Xenopus laevis, the heart starts to beat $\sim 48 \mathrm{~h}$ after fertilization (27). Blood circulation is established after a few hours, and blood starts to circulate throughout the body before heart chamber partitioning and valve formation are complete. The development of hemodynamics [i.e., blood pressure, blood flow, and heart rate $\left.\left(f_{\mathrm{H}}\right)\right]$ has been described to varying degrees for many different vertebrate taxa, including fish (33), amphibians $(7,20,21)$, reptiles (35), birds (13, 25, 34), and mammals (12). A common developmental pattern of increasing blood pressure and blood flow appears among amphibians, birds, and mammals (and presumably fish and reptiles, where it remains to be measured in detail). However, $f_{\mathrm{H}}$ shows a more varied pattern between different species within the same vertebrate group as well as between different vertebrate groups (11).

Although describing the basic hemodynamics and how they change is a necessary first step, we still know very little about the early development of the intrinsic or extrinsic regulation of cardiovascular processes in vertebrates. Probably most is known about the developing circulation of the chick embryo (see Refs. 12, 25, 29, $34)$, where extrinsic regulation is found by day 7 (16).
Among lower vertebrates, the best-understood cardiovascular system is that of the bullfrog Rana catesbeiana, in which sensitivity of the heart to cholinergic agonists and antagonists first becomes apparent at about Taylor and Kollros stage II but then changes in complex ways during development $(3,5,6,32)$.

In addition to requiring much more complete information on the onset of different cardiovascular control systems, we similarly are lacking an understanding of the influence on developing cardiovascular performance of naturally occurring environmental factors, such as hypoxia; pH, temperature, etc. Hypoxia is a particularly interesting environmental factor because embryonic hypoxia is common among vertebrates. In mammals, low $\mathrm{PO}_{2}$ can arise from imperfect placental gas exchange. Bird and reptile eggs that are brooding, laid in burrows, or buried in mounds of detritus may similarly experience varying degrees of hypoxia (1). Many freshwater fish and most amphibians lay aquatic eggs that develop in ponds and rivers that may undergo large variations in ambient $\mathrm{O}_{2}$ (and temperature) (24). Importantly, mild hypoxia is not necessarily detrimental to development, because compensating tissue level responses are evident. Developmental time in hypoxic water may be faster than in normoxic water (Fritsche, unpublished observations). Mild tissue hypoxia may also stimulate angiogenesis (11). In addition, hypoxemia in ovo may lead to the high levels of vascular and mitochondrial density required to support immediate posthatch aerobic activity (11).

Notwithstanding the purported positive effects of mild hypoxia, severe hypoxia can threaten further development once highly aerobic embryonic or larval stages are achieved. In most adult animals, exposure to hypoxia elicits different cardiovascular and respiratory reflexes, which helps the animal to deal with low $\mathrm{O}_{2}$ availability (15). The effects of hypoxic exposure on ventilation in larval amphibians are well known. Exposing larval ranids to aquatic hypoxia, for example, results in increased rates of gill ventilation in early stages and then, when lungs have developed, can result in decreased gill ventilation but increased lung ventilation $(14,36)$. These changes are orchestrated by the development of both internal and external oxygen receptors $(22,23)$. Much less is known about the development of hypoxic responses of the cardiovascular system. Exposure of larval Xenopus to acute hypoxia $\left(\mathrm{PO}_{2}=27-45 \mathrm{mmHg}\right)$ results in deceased $f_{\mathrm{H}}$ in animals between Nieuwkoop-Faber (NF) stages 51 and 54, whereas cardiac output (CO) decreased significantly at severe hypoxia in younger larvae (NF stages 44-49). Stroke volume (SV) did not change at any stage (28). Because no blood pressure measurements were made in this study, to what extent peripheral resistance 
might be actively or passively changing, for example, could not be assessed.

The present study was undertaken to investigate 1) when during development the cardiovascular system of early larvae of the African clawed frog, $X$. laevis, begins to respond (passively and actively) to changes in the water oxygen level (i.e., is there a particular time in development when cardiovascular regulation during hypoxia becomes evident?) and 2) what the effects of acute hypoxia are on the developing cardiovascular system's hemodynamics (blood pressure, $f_{\mathrm{H}}, \mathrm{SV}, \mathrm{CO}$, and vascular resistance).

\section{MATERIALS AND METHODS}

Animals. Larvae of $X$. laevis were obtained from adults bred in the laboratory or from commercial suppliers. Eggs and larvae were kept at room temperature $\left(20-22^{\circ} \mathrm{C}\right)$ on a 14:10-h light-dark photoperiod in aerated water. Larvae were fed Xenopus chow ad libitum. Larvae usually metamorphosed within $2-3 \mathrm{mo}$. The NF staging system was used (27). A total of 62 animals, ranging from NF stage $33 / 34(<1 \mathrm{mg})$ to newly metamorphosed froglets $(\sim 1 \mathrm{~g})$, were used in this study.

Measurement of blood pressure and heart rate. Animals were anesthetized in tap water containing tricaine methanesulfonate (MS222) at a concentration of $0.1 \%$ and buffered to $\mathrm{pH}$ 7.0. When movements ceased and the larvae lost buoyancy, they were transferred to the experimental chamber containing amphibian Ringer solution at $20-22^{\circ} \mathrm{C}$ and $0.1 \%$ MS222 (pH 7.8-8.0). Ringer solution rather than tap water was used as the ambient medium because recording of blood pressure required the opening of the body wall and pericardial cavity. The larva was placed ventral side up in the experimental chamber and "fenced in" using microscopic insect pins driven into a layer of transparent silicon elastomer lining the chamber bottom.

The heart and central vessels were exposed by carefully resecting the body wall and pericardium. Blood pressure was measured using a dual servo-null micropressure system (Instrumentation for Physiology and Medicine model 5D) connected to a pressure transducer (Narco model NarcoTrace 80 ). Glass microelectrodes with 2 - to 5 - $\mu \mathrm{m}$ tips were made by pulling glass capillaries $(1.0 \mathrm{~mm}$ OD) with a horizontal puller (World Precision Instruments model Pul-1). Microelectrodes were filled with a $2 \mathrm{M} \mathrm{NaCl}$ solution. The microelectrode was secured into a micromanipulator (World Precision Instruments), which was used to insert the microelectrode into the truncus arteriosus. Larvae were immediately discarded in the infrequent cases in which microelectrode insertion caused significant bleeding. Blood pressure in the truncus arteriosus $\left(\mathrm{P}_{\mathrm{tr}}\right)$ was usually stable for up to 5-6 h. Zero pressure was determined before and after blood pressure recording by placing the microelectrode in the saline pool at the same level as the measured blood vessel. Calibration of the pressure transducer was made against a static column of water. The blood pressure signal was recorded on chart paper by a NarcoTrace 80 recorder. $f_{\mathrm{H}}$ was obtained from the pulsatile blood pressure signal via a tachograph unit on the Narco recorder. $\mathrm{P}_{\mathrm{tr}}$ and $f_{\mathrm{H}}$ signals were simultaneously recorded on a computer using Sable Systems software.

Measurements of SV and $\mathrm{CO}$. SV and $\mathrm{CO}$ were determined simultaneously with $\mathrm{P}_{\mathrm{tr}}$ and $f_{\mathrm{H}}$. SV was determined using video-microscopic techniques (for details, see Refs. 7,21 ). A video camera mounted onto the microscope and connected to a S-VHS Panasonic video recorder was used for continuous filming of the heart during the experiment. The videorecorded cardiac cycles were analyzed using a personal computer equipped with a video hardware card and an image-analyzing program, Optimas Bioscan (Bioscan, Edmonds, WA). Frames containing the ventricle at exactly end systole and end diastole were selected for measurements of end-systolic volume (ESV) and end-diastolic volume (EDV). ESV and EDV were calculated from ventricular dimensions at end systole and end diastole using the formula for a prolate spheroid (see Ref. 21). SV was determined as the difference between EDV and ESV. Size calibration of the video image was made by videotaping a PE- 10 tubing $(0.61 \mathrm{~mm} \mathrm{OD})$, using the same magnification as for videotaping the ventricle.

Experimental protocol: exposure to hypoxia. The measurement chamber containing the larva was continuously supplied with aerated, temperature-controlled $\left(22^{\circ} \mathrm{C}\right)$ Ringer solution at a rate of $\sim 1 \mathrm{ml} / \mathrm{min}$ delivered by a peristaltic pump. The $\mathrm{PO}_{2}$ of the solution flowing from the experimental chamber was continuously recorded by an $\mathrm{O}_{2}$ electrode placed in series with the outflowing solution. The experiment started with the recording of $\mathrm{P}_{\mathrm{tr}}, f_{\mathrm{H}}$, and $\mathrm{SV}$ until stable readings were obtained (usually within $20-30 \mathrm{~min}$ ). Cardiovascular parameters were then recorded during a 30-min normoxic control period. Hypoxic Ringer solution at a $\mathrm{Po}_{2}$ of $70 \mathrm{mmHg}$, prepared in a separate container using a gas-mixing pump (Cameron Instruments model GF-3), was then pumped into the chamber, replacing the normoxic Ringer. The hypoxic level was set to $70 \mathrm{mmHg}$ because previous experiments on larval Xenopus revealed that critical $\mathrm{PO}_{2}$ for $\mathrm{O}_{2}$ consumption is above $70 \mathrm{mmHg}$ at all larval stages (18). In addition, this level of hypoxia was severe enough to affect the recorded cardiovascular variables. After outflowing Ringer indicated a $\mathrm{PO}_{2}$ of $70 \mathrm{mmHg}$, cardiovascular parameters were recorded for a second 30-min period of hypoxia. Finally, normoxic Ringer was pumped back into the chamber, and measurements were made during a final $30-$ min measurement period.

Data presentation and statistics. EDV and ESV of three to five consecutive cardiac cycles were measured, and mean SV values were calculated from these. This procedure was repeated every second minute during a 30 -min period before, during, and after the exposure to hypoxia. The percent change in the recorded cardiovascular variables between a mean control (prehypoxic) value and a "maximum response" value during the hypoxia was then calculated. CO was calculated by multiplying the mean SV for each 2 min by mean $f_{\mathrm{H}}$ during the same period. Vascular resistance was calculated by dividing mean $\mathrm{P}_{\text {tr }}$ during a 2 -min period by the mean $\mathrm{CO}$ for that same period. An index of cardiac work was obtained by multiplying mean $\mathrm{P}_{\mathrm{tr}}$ by $\mathrm{CO}$.

The data were tested for normal distribution, and statistical significance was tested by analysis of variance followed by Student-Newman-Keuls test. Significant differences were tested for between the normoxic and hypoxic yalue for each cardiovascular variable and stage and between the hypoxic response in the early stages $(45-48)$ and the later stages. A fiducial level of $P \leq 0.05$ was employed.

\section{RESULTS}

Ontogeny of hemodynamics. In Xenopus embryos, the heart starts to beat at $30-40$ beats $/ \mathrm{min}$. Then $f_{\mathrm{H}}$ increases rapidly, reaching $80-110$ beats/min after 22 h. After this initial rise, $f_{\mathrm{H}}$ decreases throughout the rest of development. This study is the first to report blood pressure immediately after the onset of heartbeat. At the beginning of heartbeat, diastolic $P_{t r}$ is 0.2 $\mathrm{mmHg}$ and the systolic $\mathrm{P}_{\mathrm{tr}}$ is $0.7 \mathrm{mmHg}$ (Fig. 1). Subsequently, mean $P_{t r}$ increases linearly with $\log$ body mass throughout the whole course of development in 


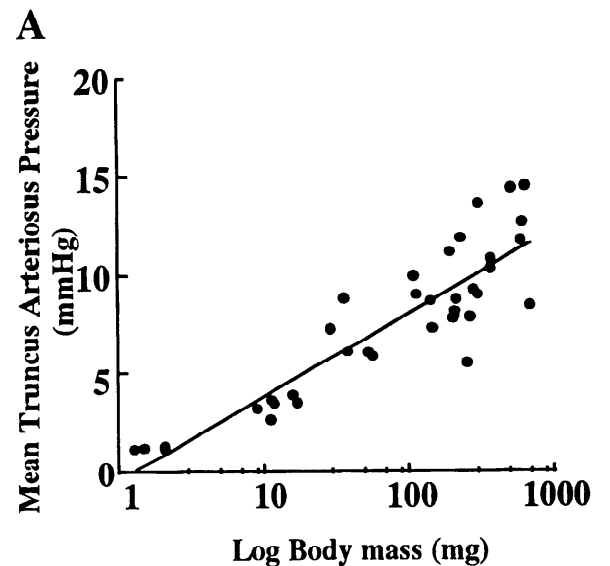

B

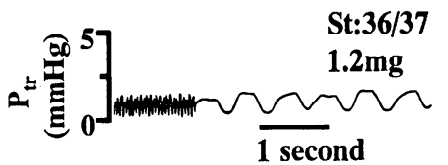

Fig. 1. A: mean blood pressure in the truncus arteriosus $\left(\mathrm{P}_{\mathrm{tr}}\right)$ in larval Xenopus laevis vs. log body mass. $B$ : original recording of $\mathrm{P}_{\mathrm{tr}}$ in larval Xenopus [stage (St) 36/37; body mass $1.2 \mathrm{mg}$ ] recorded a few hours after onset of heartbeat.

Xenopus. Two distinct peaks on the truncus pressure waveform, previously reported at NF stage 48 by Hou and Burggren (20), are present even earlier in development at NF stage 37/38. This reaffirms and extends the importance of conus contraction to overall blood flow in these early stages (Fig. 1).

Cardiovascular responses to hypoxia in larval Xenopus. Figure 2 shows a representative original recording of $\mathrm{P}_{\mathrm{tr}}$ and $f_{\mathrm{H}}$ during hypoxia in early (NF stage 45 ) and late (NF stage 57) larvae. Larvae responded to acute aquatic hypoxia $\left(\mathrm{PO}_{2}=70 \mathrm{mmHg}\right)$ with a significant bradycardia at all but the earliest stages (NF stages 45-48) (Fig. 3A). Bradycardia developed within 5 min after the onset of hypoxia and lasted throughout the hypoxic period. $\mathrm{P}_{\mathrm{tr}}$ decreased significantly at NF stages 45-48 during hypoxia. By NF stages 54-57, this decrease in $\mathrm{P}_{\mathrm{tr}}$ reversed to a significant increase during hypoxia (Fig. $3 B$ ). In the later stages (NF stages 58-62 and in froglets), no significant hypoxic effect on $\mathrm{P}_{\text {tr }}$ occurred (Fig. $3 B$ ). SV decreased significantly at the earlier stages (NF stages 45-48), but this decrease was reversed to a significant increase at NF stages $52-53$
(Fig. 3C). At later stages, hypoxic exposure caused no significant change in SV but the response was significantly different from that occurring in young (stages 45-48) larvae (Fig. 3C). CO showed a pattern of change similar to that of SV during hypoxia. A significant decrease in $\mathrm{CO}$ occurred at earlier stages (NF stages 45-48). At NF stages 52-53 and older, hypoxic exposure resulted in insignificant or relatively small if significant (stages 58-62) changes in $\mathrm{CO}$. However, the hypoxic response in stage 52-53 and 54-57 larvae was significantly different from the hypoxic response occurring in young (stages 45-48) larvae (Fig. $3 D$ ). Interestingly, peripheral vascular resistance increased in the earlier stages (NF stages 45-48 and 49-51) during hypoxia. At NF stages 52-53, peripheral resistance decreased, but no significant hypoxic effects were found in the later larval stages (Fig. $3 E$ ). In froglets, peripheral resistance decreased significantly during hypoxia (Fig. $3 E$ ). Cardiac work was significantly reduced in the earliest larvae (NF stages 45-48) and significantly increased in froglets during hypoxia (Fig. $3 F$ ). The hypoxia-induced change in cardiac work in stage 45-48 larvae was significantly different from the response of stage 52-53 and 54-57 larvae and froglets. These data make apparent the fact that two different patterns of responses to hypoxia exist in early and late developing tadpoles of $X$. laevis (Fig 2).

A cardiac arrythmic pattern occurred during the hypoxic period in $80 \%$ of the animals. These periods were characterized by sudden drops in $f_{\mathrm{H}}$ lasting for 10-30 s before $f_{\mathrm{H}}$ increased again (Fig. 4).

\section{DISCUSSION}

Ontogeny of hemodynamics. $f_{\mathrm{H}}$ is the most wellcharacterized hemodynamic variable in the developing vertebrate cardiovascular system. Initially, $f_{\mathrm{H}}$ is slow, and a rapid increase in $f_{\mathrm{H}}$ appears to be nearly universal in all species studied $(6,19,30,31)$. After this initial rapid increase, the pattern of $f_{\text {II }}$ development differs largely between vertebrate taxa, and no common pattern seems to exist within or between different vertebrate groups. In the amphibian $R$. catesbeiana, $f_{\mathrm{H}}$ changes during development are explained almost completely by changes in body mass (W. Burggren and P. Territo, unpublished observations). In the direct-

Fig. 2. Original recording of $\mathrm{P}_{\mathrm{tr}}$, heart rate $\left(f_{\mathrm{H}}\right)$, and $\mathrm{PO}_{2}$ of larvae in water, showing response to acute aquatic hypoxia in early (stage $45 ; A$ ) and late (stage 57 ; $B$ ) larval Xenopus.

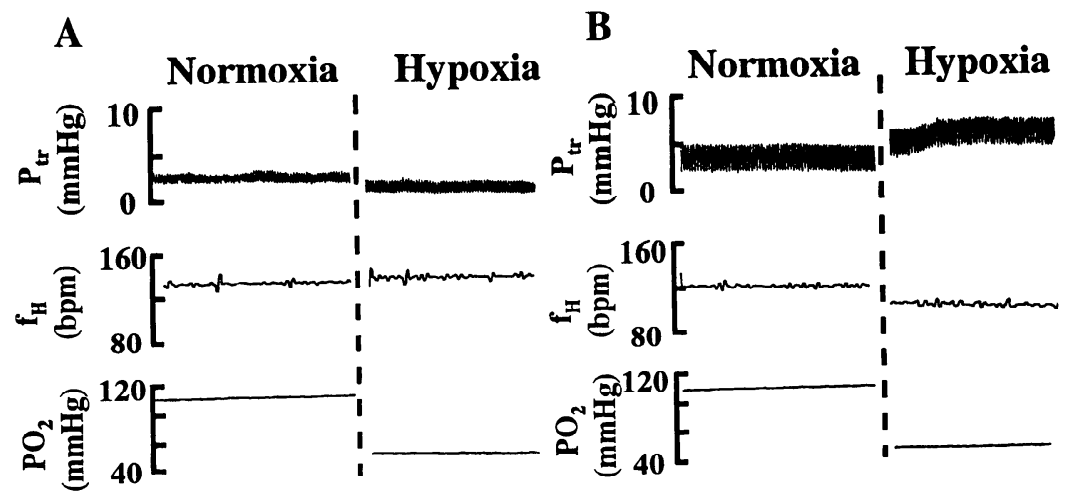



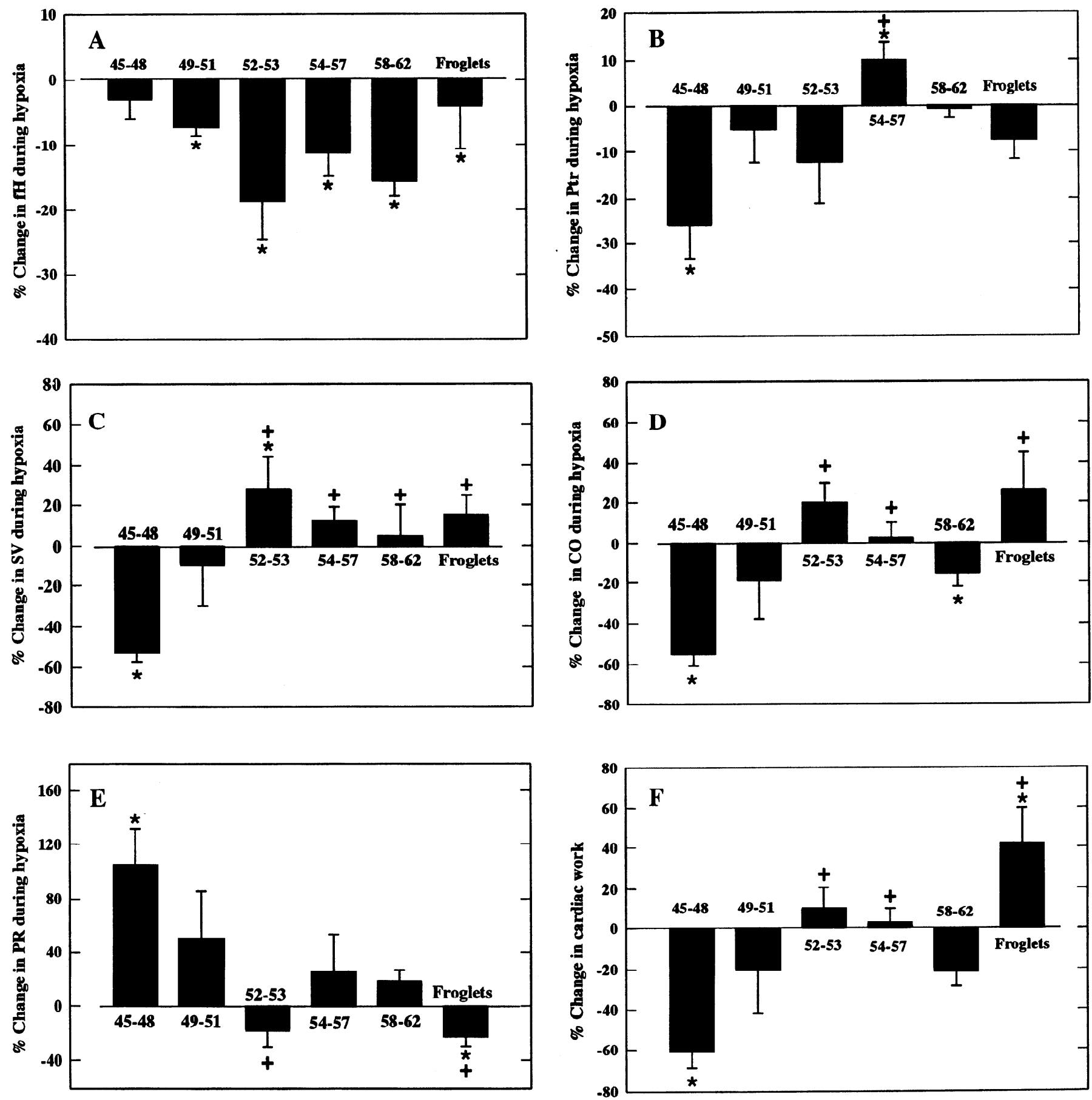

Fig. 3. Cardiovascular responses to hypoxia in larval Xenopus at different stages of development. Values shown are means \pm SE. SV, stroke volume; CO, cardiac output; PR, peripheral resistance. * Statistically significant difference from the prehypoxic control value; ${ }^{+}$statistically significant difference from the hypoxic response at stages $45-48$.

developing frog, Eleutherodactylus coqui, $f_{\mathrm{H}}$ rises during development despite little change in embryo mass (8). Thus, in some species, body mass alone seems to influence changes in $f_{\mathrm{H}}$ (so-called allometric effects),

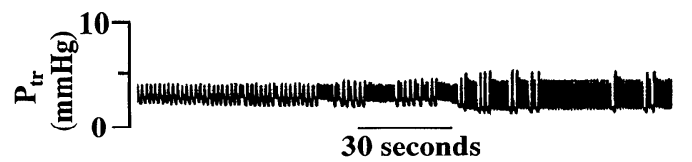

Fig. 4. Original recording showing the frequent pattern of arrythmias (sudden drops in $f_{\mathrm{H}}$ ) found in late larvae during the hypoxic period. whereas in other species tissue and organ formation per se seems to be most influential on $f_{\mathrm{H}}$. In $X$. laevis, the heart beats at a rate of $30-40$ beats/min at the onset of heartbeat $\left(22^{\circ} \mathrm{C}\right.$, normoxia). A rapid increase in $f_{\mathrm{H}}$ up to $80-100$ beats $/ \mathrm{min}$ is observed during the following $22 \mathrm{~h}$ of development. During the subsequent development, $f_{\mathrm{H}}$ decreases, reaching adult levels of 50-60 beats/min (see Ref. 11). The mechanisms behind the varying patterns of developmental changes in $f_{\mathrm{H}}$ have not received much attention but probably involve changes in membrane ion permeability, differential 
rate of development of adrenergic and cholinergic control, onset of hormonal control, as well as developmental changes in the pacemaker region (11).

The development of advanced "microtechniques" now permit hemodynamic measurements not previously possible in animals weighing only a few milligrams (see Ref. 7). Blood pressure increases dramatically during early development in all vertebrates studied $(13,20$, 30 ). To date, the earliest pressure measurement made in $X$. laevis are at NF stage $48(\sim 20 \mathrm{mg})(20)$, and indeed no pressure measurement immediately after the onset of heartbeat has to our knowledge been made in any vertebrate or invertebrate. Figure 1 shows the developmental pattern of blood pressure from the beginning of heartbeat in Xenopus. Blood pressure clearly rises linearly with increasing log body mass throughout development. Most species show this allometric relationship between blood pressure and body mass during development. An exception is the paradoxical frog, Pseudis paradoxus, in which blood pressure rises during development despite a decline in body mass at the same time (4).

Cardiovascular responses to hypoxia in larval Xenopus. Acute hypoxic exposure of larval Xenopus has revealed two patterns of cardiovascular responses (Fig. 2). In early larvae (NF stages 45-48 and 49-51), hypoxia causes a depression of heart function, presumably through direct effects on the cardiac muscle of the heart and smooth muscle of the blood vessels. At these stages, there appears to be no regulatory ability of the cardiovascular system. SV and CO decreased significantly during hypoxia at stages $45-48$ (Fig. 3, $C$ and $D$ ), as did $\mathrm{P}_{\mathrm{tr}}$ and cardiac work. Interestingly, peripheral resistance increased during this same period (Fig. $3 E$ ). It is possible that a reduced $\mathrm{CO}$ concomitant with a decrease in central blood pressure caused capillary blood pressure to fall below critical closing pressure, collapsing peripheral vessels. Peripheral resistance rises not only because the vessel diameter is decreased because of lowered transmural pressure but also according to the "law of Laplace," where a decrease in vessel diameter causes the force of stretch to decrease. In adult vertebrates, hypoxia usually results in a decreased peripheral resistance due to a direct dilatory effect on most peripheral vessels (17). The froglets in this study do indeed decrease peripheral resistance during hypoxia.

Unlike earlier stages in which hypoxia depresses SV, at later stages (beyond stages 52-53) hypoxia significantly increases SV (Fig. 3C). The hypoxic response of CO shows the same reversal with further development (Fig. $3 D$ ), and peripheral resistance decreases instead of increases at the same time (Fig. $3 E$ ). The "switch" in $\mathrm{P}_{\mathrm{tr}}$ from a passive decrease to an increase is delayed to stages 54-57 compared with the SV and CO changes (Fig. $3 B) . f_{\mathrm{H}}$ is the only variable showing a common hypoxic response (bradycardia) in almost all developmental groups. Only the earliest group failed to develop a bradycardia (Fig. $3 A$ ). No hypoxic bradycardia was found in larval salmonid fish $(19,26)$. Among amphibians, newly hatched larval $R$. catesbeiana show hypoxic bradycardia, probably due to a direct cardiac depression (2). Early Rana berlandieri exhibited a mild bradycardia that switched to a tachycardia in older larvae (14). As in the present study, Orlando and Pinder (28) report a reduction in $f_{\mathrm{H}}$ in response to hypoxia in all stages of Xenopus larvae. Orlando and Pinder (28) also found a decrease in $\mathrm{CO}$ in younger Xenopus larvae (stages 44-49) exposed to severe hypoxia $\left(\mathrm{PO}_{2}=27-45\right.$ $\mathrm{mmHg}$ ) but no effect on SV. In their study, the animals were divided into two developmental groups only: "younger" (NF stages 44-49) and "older" (NF stages 51-54). No switch from a passive effect of hypoxia to active regulation could be distinguished (28).

The findings that early and late larval $X$. laevis show different cardiovascular response patterns to acute aquatic hypoxia suggest that there is a specific time (i.e., between stages $49-51$ and 52-53) when cardiovascular regulation, at least during hypoxia, becomes functional in this species. Anatomic innervation of the ventricle in Xenopus is found at stage 49 (27). Therefore, the onset of cardiovascular regulation coincides with the anatomic appearance of nerves growing into the ventricle. The development of cardiovascular control systems is poorly understood, but it is generally agreed that the receptors for a certain neurotransmitter or hormone develop earlier that the functional innervation $(29,34)$. In chick and also in most mammalian embryos, the receptors are already developed at the onset of heartbeat (29). Also, in Xenopus embryos, topically applied acetylcholine induces cardiac inhibition in very early larvae in which the heart has just begun to beat (Fritsche, unpublished observations). It is possible that the cardiovascular depression observed in early embryos of Xenopus in this study is a result of hypoxia acting directly on the muscle fibers of the heart and vasculature in the absence of functional innervation. In older larvae, these tissues appear to be actively regulated during hypoxic exposure.

Another interesting finding is the reversal of the relationship of SV and $f_{\mathrm{H}}$ between stages $49-51$ and 52-53. Prior to this point in development, the simultaneous fall in both $\mathrm{SV}$ and $f_{\mathrm{H}}$ suggests little intrinsic regulation of $\mathrm{CO}$. After this point in development, the inverse relationship between $\mathrm{SV}$ and $f_{\mathrm{H}}$ is highly suggestive of a functional Frank-Starling relationship as evident in mature hearts. Early development of a Frank-Starling mechanism has similarly been documented in the early chick embryo prior to cardiac innervation (see Ref. 25 for references).

Conclusions. Two different cardiovascular response patterns to acute aquatic hypoxia in early (NF stages 45-48 and 49-51) and late (NF stages 52-53, 54-57, and 58-62) larval Xenopus were found in this study. These findings suggest that there is a specific point in development when cardiovascular regulation during hypoxia is expressed. At earlier stages, hypoxia exerts a direct inhibitory action on the heart and smooth muscle of the vessels. The regulated cardiovascular responses are similar to those found in many adult species of lower vertebrates during hypoxic exposure. The mechanisms of control acting on the cardiovascular system during hypoxia in older larvae are yet to be determined. 
This study was supported by a Swedish Natural Science Research Foundation postdoctoral scholarship to R. Fritsche and by National Science Foundation Operating Grant IBN-9307832 to W. Burggren.

Present address of $R$. Fritsche and address for reprint requests: Dept. of Zoophysiology, Univ. of Göteborg, Medicinaregatan 18A, 413 90 Götcborg, Sweden.

Received 27 December 1995; accepted in final form 26 March 1996.

\section{REFERENCES}

1. Boggs, D. F., D. L. Kilgore, Jr., and G. F. Birchard. Respiratory physiology of burrowing mammals and birds. Comp. Biochem. Physiol. A Comp. Physiol. 77: 1-7, 1984.

2. Burggren, W. W. Transition of respiratory processes during amphibian metamorphosis: from egg to adult. In: Respiration and Metabolism of Embryonic Vertebrates, edited by R. S. Seymour. The Hague: Junk, 1984, p. 31-53.

3. Burggren, W. W. Central cardiovascular function in amphibians: qualitative influences of phylogeny, ontogeny and seasonality. In: Mechanisms of Systemic Reyulation. Respiration and Circulation, edited by N. Heisler. Berlin: Springer-Verlag, 1995, vol. 1.

4. Burggren, W. W., J. E. Bicudo, M. L. Glass, and A. S. Abe. Development of blood pressure and cardiac reflexes in the frog Pseudis paradoxsus. Am. J. Physiol. 263 (Regulatory Integrative Comp. Physiol. 32): R602-R608. 1992.

5. Burggren, W. W., and M. Doyle. The action of acetylcholine upon heart rate changes markedly with development in the bullfrog. J. Exp. Zool. 240: 137-140, 1986.

6. Burggren, W. W., and M. Doyle. Ontogeny of heart rate regulation in the bullfrog, Rana catebeiana. Am. J. Physiol. 251 (Regulatory Integrative Comp. Physiol. 20): R231-R239, 1986.

7. Burggren, W. W., and R. Fritsche. Cardiovascular measurements in animals in the milligram body mass range. Braz. J. Med. Biol. Res. 28: 1291-1305, 1995.

8. Burggren, W. W., R. L. Infantino, and D. S. Townsend. Developmental changes in cardiac and metabolic physiology of the direct-developing frog, Eleutherodactylus coqui. J. Exp. Biol. 152: 129-147, 1990

9. Burggren, W. W, and B. Keller (Editors). Development of the Cardiovascular Systems: Molecules to Organisms. New York: Cambridge Univ. Press. In press.

10. Burggren, W. W., and A. W. Pinder. Ontogeny of cardiovascular and respiratory physiology in lower vertebrates. Annu. Rev. Physiol. 53: 107-135, 1991.

11. Burggren, W. W., and S. Warburton. Patterns of form and function in developing hearts: contributions from non-mammalian vertebrates. Cardioscience 5: 183-191, 1994.

12. Clark, E. B. Growth, morphogenesis and function: the dynamics of cardiac development. In: Fetal, Neonatal and Infant Heart Disease, edited by J. H. Moller, W. Neal, and J. Lock. East Norwalk, CT: Appleton-Lang, 1989, p. 1-17.

13. Clark, E. B., and N. Hu. Developmental hemodynamic changes in the chick embryo stages 18 to 27. Circ. Res. 51: 810-815, 1982.

14. Feder, M. E. Responses to acute aquatic hypoxia in larvae of the frog Rana berlandieri. J. Exp. Biol. 104: 79-95, 1983.

15. Fritsche, R., and S. Nilsson. Cardiovascular and ventilatory control during hypoxia. In: Fish Physiology. London: Chapman and Hall, 1993, chapt. 7, p. 180-206.

16. Girard, H. Adrenergic sensitivity of circulation in the chick embryo. Am. J. Physiol. 224: 461-469, 1973.

17. Guyton, A. C. Medical Physiology (7th ed.). Philadelphia, PA: Saunders, 1986
18. Hastings, D., and W. W. Burggren. Developmental changes in oxygen consumption regulation in larvae of the south African clawed frog, Xenopus laevis. J. Exp. Biol. 198: 2465-2475, 1996.

19. Holeton, G. F. Respiratory and circulatory responses of rainbow trout larvae to carbon monoxide and to hypoxia. J. Exp. Biol. 55: 683-694, 1986.

20. Hou, P.-C. L., and W. W. Burggren. Blood pressures and heart rate during larval development in the anuran amphibian Xenopus laevis. Am. J. Physiol. 269 (Regulatory Integrative Comp. Physiol. 38): R1120-R1125, 1995.

21. Hou, P.-C. L., and W. W. Burggren. Cardiac output and peripheral resistance during larval development in the anuran amphibian Xenopus laevis. Am. J. Physiol. 269 (Regulatory Integrative Comp. Physiol. 38): R1126-R1132, 1995.

22. Infantino, R. Ontogeny of Ventilatory Regulation in the Bullfrog Rana Catesbeiana (PhD dissertation). Amherst, MA: Univ. of Massachusetts, 1991.

23. Jia, X. Chemoreceptor Modulation of Gill Ventilation in the Larval Bullfrog Rana Catesbeiana (PhD dissertation). Amherst, MA: Univ. of Massachusetts, 1991.

24. Jorgensen, C. B. Development, and reproduction. In: Environmental Physiology of the Amphibians, edited by M. E. Feder and W. W. Burggren. Chicago, IL: Univ. of Chicago Press, 1992, p. $437-466$.

25. Keller, B. Embryonic cardiovascular function, coupling, and maturation. In: Development of the Cardiovascular Systems: Molecules to Organisms, edited by W. W. Burggren and B. Keller. New York: Cambridge Univ. Press. In press.

26. McDonald, G., and B. R. Mcmahon. Respiratory development in Arctic char Salvelinus alpinus under conditions of normoxia and chronic hypoxia. Can. J. Zool. 55: 1461-1467, 1977.

27. Nieuwkoop, P. D., and J. Faber. Normal Table of Xenopus laevis. Amsterdam: North-Holland, 1967.

28. Orlando, K., and A. W. Pinder. Larval cardiorespiratory ontogeny and allometry in Xenopus laevis. Physiol. Zool. 68: 63-75, 1995

29. Pappano, A. J. Ontogenetic development of autonomic neuroeffector transmission and transmitter reactivity in embryonic and fetal hearts. Pharmacol. Rev. 29: 3-33, 1977.

30. Pelster, B., and W. E. Bemis. Ontogeny of heart function in the little skate, Raja erinacea. J. Exp. Biol. 156: 387-398, 1991.

31. Pelster, B., and W. W. Burggren. Central arterial hemodynamics in larval bullfrogs (Rana catesbeiana): developmental and seasonal effects. Am. J. Physiol. 260 (Regulatory Integrative Comp. Physiol. 29): R240--R246, 1991.

32. Pelster, B., W. W. Burggren, S. Petrou, and I. Wahlqvist. Developmental changes in the acetylcholine influence on heart muscle of Rana catesbeiana: in situ and in vitro effects. J. Exp. Zool. 267: 1-8, 1993.

33. Rombough, P. Piscine cardiovascular development. In: Development of the Cardiovascular Systems: Molecules to Organisms. New York: Cambridge Univ. Press. In press.

34. Tazawa, H., and P.-C. L. Hou. Avian cardiovascular development. In: Development of the Cardiovascular Systems: Molecules to Organisms. New York: Cambridge Univ. Press. In press.

35. Warburton, S. Reptilian cardiovascular development. In: Development of the Cardiovascular Systems: Molecules to Organisms. New York: Cambridge Univ. Press. In press.

36. West, N. H., and W. W. Burggren. Respiratory response to steady-state aquatic hypoxia and hyperoxia in the bullfrog tadpole. Respir. Physiol. 47: 165-176, 1982. 